\title{
Demographic and psychosocial predictors of acute perioperative pain for total knee arthroplasty
}

\author{
Maya L Roth MA , Dean A Tripp $\mathrm{PhD}^{2}$, Mark H Harrison $\mathrm{MD}^{3,4}$, Michael Sullivan $\mathrm{PhD}^{5}$, Patricia Carson $\mathrm{BSc}^{4}$
}

\begin{abstract}
ML Roth, DA Tripp, MH Harrison, M Sullivan, P Carson. Demographic and psychosocial predictors of acute perioperative pain for total knee arthroplasty. Pain Res Manage 2007;12(3):185-194.
\end{abstract}

BACKGROUND: As the North American population ages, the prevalence of knee osteoarthritis and the surgical interventions (ie, total knee arthroplasty [TKA]) aimed at correcting pain and disability will also rise proportionally. Therefore, efforts to better understand the factors associated with surgical outcomes are warranted. To date, no studies have examined the impact of psychosocial factors on acute postoperative TKA pain.

OBJECTIVES: The primary objective was to examine the associations among catastrophizing, negative mood, demographics and acute postoperative pain following TKA. Ancillary analyses examined the association of preoperative psychological variables with postoperative pain.

METHODS: Patients completed questionnaire packages $2 \mathrm{~h}$ before their surgery and on three consecutive postoperative days while in the hospital. The questionnaire packages included the Short Form McGill Pain Questionnaire, the Pain Catastrophizing Scale and the Shortened Version of Profile of Mood States. The Mini-Mental State Examination was also administered. Demographic data were extracted from patients' medical charts.

RESULTS: Associations among catastrophizing, negative mood and pain were established. Regressions showed that younger age predicted greater preoperative and postoperative day 1 pain; catastrophizing predicted preoperative and postoperative day 2 pain; and negative mood predicted postoperative day 3 pain. Catastrophizing and negative mood were highly correlated at several assessment points. Preoperative variables did not predict postoperative pain.

CONCLUSION: These results have postoperative pain management implications. Heightened attention to psychosocial variables, such as postoperative catastrophizing and negative mood, may be useful in identifying patients at risk for greater postoperative pain.

Key Words: Acute postoperative pain; Older adults; Osteoarthritis; Total knee arthroplasty

Surgical outcomes research has increased dramatically in recent years, attempting to make surgery as safe, effective and unproblematic for patients as possible (1). Due to the striking increases expected in the older North American adult population in the next 30 years, this cohort has attracted increased clinical interest of late. Individuals 65 years of age and older are the fastest growing cohort in Canada (2); they will go on to constitute approximately one in four Canadians and will require large investments in health care expenditures (3).

Arthritis is the largest chronic health condition in older adults (2). Osteoarthritis (OA), the most common form of

\section{Les prédicteurs démographiques et psychosociaux des douleurs périopératoires aiguës causées par une arthroplastie totale du genou}

HISTORIQUE : À mesure que vieillit la population nord-américaine, la
prévalence d'arthroses du genou et d'interventions chirurgicales (c'est-à-
dire d'arthroplasties totales du genou, ou ATG) visant à corriger la
douleur et l'invalidité augmentera proportionnellement. Par conséquent,
il faut consentir des efforts pour mieux comprendre les facteurs reliés aux
issues chirurgicales. Jusqu'à présent, aucune étude n'a traité des répercus-
sions des facteurs psychosociaux sur les douleurs postopératoires aiguës
causées par l'ATG. OBJECTIFS : L'objectif principal consistait à examiner les associations entre la catastrophisation, les humeurs négatives, la démographie et la douleur postopératoire aiguë après une ATG. Des analyses auxiliaires ont porté sur l'association entre des variables psychologiques préopératoires et la douleur postopératoire.

MÉTHODOLOGIE : Les patients ont rempli la série de questionnaires deux heures avant l'opération et trois jours consécutifs après l'opération pendant qu'ils étaient hospitalisés. La série de questionnaires se composait du questionnaire court sur la douleur de McGill, de l'échelle de catastrophisation de la douleur et de la version courte du profil des états d'humeur. Le mini-examen sur l'état mental a également été administré. RÉSULTATS : On a établi des associations entre la catastrophisation, l'humeur négative et la douleur. Les analyses de régression ont démontré qu'un âge plus jeune prédisait une plus grande douleur préopératoire et le premier jour après l'opération; la catastrophisation, des douleurs préopératoires et le deuxième jour après l'opération; et l'humeur négative, des douleurs le troisième jour après l'opération. La catastrophisation et l'humeur négative étaient fortement corrélées à divers points d'évaluation. Les variables préopératoires ne permettaient pas de prédire les douleurs postopératoires.

CONCLUSION : Ces résultats ont des conséquences sur la prise en charge de la douleur après une opération. Il peut être utile d'accorder plus d'attention aux variables psychosociales, comme la catastrophisation postopératoire et l'humeur négative, pour repérer les patients vulnérables à de plus fortes douleurs postopératoires.

arthritis, is a degenerative joint disease usually affecting the knee and hip joints (4-7). OA affects approximately one in 10 individuals and is equally prevalent in men and women, although there is higher prevalence in postmenopausal and obese women $(4,7,8)$. OA occurrence is positively correlated with age and has a mean age of onset of 45 years $(4,6)$. It is a major cause of morbidity, activity limitation and health care utilization in older adults, and psychosocial sequelae include depression, stress and diminished quality of life $(\mathrm{QoL})(4,6)$.

The high prevalence of knee $O A$ is directly associated with a rising number of surgical interventions designed to reduce

${ }^{1}$ Department of Psychology, York University, Toronto, Ontario; ${ }^{2}$ Departments of Psychology, Anesthesiology Ë Urology, Queen's University,

Kingston, Ontario; ${ }^{3}$ Department of Surgery, Queen's University, Kingston, Ontario; ${ }^{4}$ Human Mobility Research Centre, Queen's University,

Kingston, Ontario; ${ }^{5}$ Department of Psychology, McGill University, Montreal, Quebec

Correspondence: Ms Maya L Roth, Department of Psychology, Behavioural Sciences Building, York University, 4700 Keele Street, Toronto,

Ontario M3J 1P3. Telephone 416-733-5115, fax 416-736-5814, e-mail mayar@yorku.ca 
pain and increase mobility for patients (ie, total knee arthroplasty [TKA]). While the majority of patients report satisfaction with outcomes following TKA $(9,10)$, and it has been shown to be effective in improving pain, physical function and QoL (11), 10\% to $15 \%$ of patients do not report improved QoL $(12,13)$. With the exception of demographic factors (ie, age, sex and weight) and medical factors (ie, medical comorbidity and preoperative morbidity), the orthopedic literature has few studies examining psychosocial factors in TKA outcomes (12).

Pain is the most debilitating symptom of knee OA and is the motivator for patients seeking treatment (14). Demographic variables (eg, age, sex and weight), medical comorbidity and psychological variables (eg, fatigue, depression and anxiety) are predictors of pain severity in knee OA (14). Furthermore, pain is suggested to be a dominant feature of the TKA procedure and has implications for short- and long-term recovery $(1,15,16)$, with higher postoperative pain associated with increased length of stay, delayed ambulation and long-term functional impairment (16). Pain is conceptualized as a physiological/psychological experience (17). This conceptualization emphasizes the importance of cognitive and affective variables such as catastrophizing $(18,19)$ and depressive symptoms $(20,21)$.

Demographic variables (ie, age and sex) are associated with pain in general chronic pain conditions as well as knee OA pain $(5,14,22)$. Numerous studies have reported that pain intensity, interference and disability increases with age in both knee $\mathrm{OA}$ and chronic pain $(5,22,23)$. Interestingly, recent data suggest that in chronic pain cohorts, older adults (60 to 81 years of age) reported less distress compared with younger (18 to 39 years of age) and middle-aged adults (40 to 59 years of age) (24). Data on sex and pain provide a consensus that pain is more common among women, and that women report greater pain intensity and longer pain duration in both knee $O A$ and chronic pain $(5,22-24)$. More specifically, women with knee $\mathrm{OA}$ report greater pain-related disability and complaints compared with their male counterparts $(5,22)$.

In regard to psychosocial variables and pain, catastrophizing has been associated with greater pain and emotional distress (25-27). Catastrophizing, defined as an exaggerated negative mental state invoked during an actual or anticipated painful experience (26), is associated with thoughts that are negative and ruminatory in nature, place excessive focus on the negative aspects of the pain experience, emphasize and magnify pain sensations, and evoke feelings of hopelessness and inability to cope effectively with pain $(25,26,28)$. Catastrophizing is one of the most robust psychological predictors of pain experience $(25,26,29)$, and is associated with more complicated postoperative recoveries, greater postoperative pain and greater analgesic consumption $(26,30,31)$. For example, Keefe et al (25) examined pain in arthritis patients one year following TKA, and found catastrophizing to be associated with both greater pain and disability.

Although few studies have examined preoperative catastrophizing's prediction of postoperative pain, it has been shown that preoperative catastrophizing predicted pain immediately following surgery and on postoperative day 7 in a sample of patients following surgery to repair the anterior cruciate ligament (ACL) (32), and that preoperative catastrophizing predicted pain when controlling for anxiety on postoperative days 1 and 2 in an abdominal surgical sample (33). To date, there are no data examining the association between preoperative and postoperative catastrophizing and postoperative pain following TKA.

Negative mood has also been shown to exacerbate pain, with emphasis placed on depressive and anxious states $(27,31)$. Depressive symptoms are positively associated with pain intensity ratings $(27,34)$, and this relationship has been established among patients with chronic lower back pain (34), OA (25) and fibromyalgia (35). Keefe et al (36) state that depression exacerbates arthritis symptoms, impairs function and leads to worse health outcomes. Pain is also positively correlated with anxiety, but much of the evidence suggesting this relationship is derived from laboratory-based acute pain. These laboratorybased studies show that pain-related anxiety exacerbates pain perception (30). There is also evidence that anxiety is related to pain severity in knee OA patients (14).

The most prominent outcome variable associated with $\mathrm{OA}$ and TKA is pain $(1,11,15,16)$. Thus, the current study attempts to examine the psychosocial determinants of postoperative pain in a TKA sample. The primary aim of the present study was to examine the association of psychosocial variables on acute postoperative outcome following TKA. Ancillary analysis examined the association of preoperative psychosocial variables with postoperative pain. There were several hypotheses: older age and female sex would be associated with preoperative and postoperative pain; postoperative catastrophizing and negative mood would be associated with greater postoperative pain; and preoperative catastrophizing and negative mood would be associated with greater preoperative and postoperative pain.

\section{Participants}

\section{METHODS}

Ninety-nine surgical wait-list patients were recruited from the orthopedic service (Dr Mark Harrison and four colleagues) at the Kingston General Hospital in Kingston, Ontario, for participation in the present study. Of the 99 recruited patients, 68 (69\%) consented to participate, with 31 patients not participating due to surgery change or cancellation $(14 \%)$, withdrawal from the study $(11 \%)$, patients having undergone different surgeries $(4 \%)$ and administration errors (2\%). Although all 68 participating patients completed the preoperative and postoperative questionnaires, several participants did not complete the questionnaire packages at all four data collection points.

Sample division: Due to patient attrition and missing data, the sample sizes for the preoperative and postoperative days 1 , 2 and 3 assessment points fluctuate. To maximize the sample size and statistical power of analyses, data were divided into subgroups. The intraday or between patients' data subgroups (ie, preoperative and postoperative days 1 to 3 ) were used primarily to examine the hypotheses associated with postoperative analyses. These data points were made up of all patients completing the questionnaires at each of the individual assessment points. The longitudinal data examines hypothesis 3, and is comprised of the within-patients sample providing complete data across all assessment points. In the longitudinal sample, 18 patients were excluded from the original 68 consenting patients due to incomplete data. Consequently, 50 patients provided complete data in the longitudinal subgroup (26 women, mean \pm SD age $71 \pm 8.9$ years). A total of 63 patients provided complete data for the preoperative 
intraday subgroup (34 women, mean age $70 \pm 8.8$ years), 58 patients completed the postoperative day 1 assessment (32 women, mean age $70.64 \pm 9.26$ years), 60 patients for postoperative day 2 ( 32 women, mean age $70.17 \pm 8.9$ years) and 52 patients for postoperative day 3 (31 women, mean age $70.9 \pm 8.6$ years $)$.

\section{Measures}

Demographic and medical information were extracted from patient's medical charts by the first author. The information included demographics such as age, height, weight, body mass index score, sex, marital status and surgeon (Table 1).

\section{Questionnaires}

Mini-Mental State Examination (37): The Mini-Mental State Examination (MMSE) is a brief, quantitative measure of cognitive status for adults and was used in the present study to examine cognitive status of surgical patients. An MMSE cutoff of 24 has been used in surgical populations to screen for impairment (38), and was used in the present study. The MMSE has good internal consistency, is stable over time and was used in the present study to assess cognitive status at both preoperative and postoperative day 1 to control for possible patient disorientation that is often associated with acute postoperative assessment.

Short Form - McGill Pain Questionnaire (39): The Short Form - McGill Pain Questionnaire (SF-MPQ) consists of 15 descriptors, 11 of which describe sensory aspects of pain and four that describe affective dimensions of pain. Each pain descriptor is endorsed by score anchors, with ' $O$ ' indicating 'none', ' 1 ' indicating 'mild', '2' indicating 'moderate' and ' 3 ' indicating 'severe'. Pain scores are derived from the sum of the intensity rank values of the words chosen. The SF-MPQ is a reliable and valid measure, commonly used in clinical applications $(39,40)$. In the current study, the degree of internal consistency on the SF-MPQ was $\alpha=0.86$.

Pain Catastrophizing Scale (18): The Pain Catastrophizing Scale (PCS) is a 13-item scale in which patients reflect on their pain and indicate the extent to which they endorse certain statements. Each statement is rated on a five-point scale that ranges from ' 0 ' indicating 'not at all' to ' 4 ' indicating 'all the time'. The statements correspond to three positively correlated factors of catastrophizing: rumination (eg, "I can't stop thinking about how much it hurts"), magnification (eg, "I'm afraid something serious will happen") and helplessness (eg, "There's nothing I can do to reduce the intensity of the pain"). PCS scores range from 0 to 52, with lower scores indicative of less catastrophizing. The PCS has adequate test-retest reliability and good validity (18). In the current study, PCS internal consistency was $\alpha=0.86$.

Shortened Version of Profile of Mood States (41): The Shortened Version of Profile of Mood States (SPOMS) is a 37-item self-report adjective checklist, assessing six mood or affective states, including tension-anxiety, depressiondejection, anger-hostility, vigor-activity, fatigue-inertia and confusion-bewilderment. Participants reflect on feelings experienced over the past $24 \mathrm{~h}$ and rate each adjective on a five point-scale that ranges from ' 0 ' indicating 'not at all' to '4' indicating 'extremely'. SPOMS scores range from 0 to 148 , where lower scores are indicative of lower levels of the abovementioned emotional states. The SPOMS scale has excellent test-retest reliability and internal consistencies, ranging from
TABLE 1

Demographic characteristics of the sample

\begin{tabular}{lccccc}
\hline Variable & LONG data & Preop & PD1 & PD2 & PD3 \\
\hline Age, years & 71.89 & 70 & 70.64 & 70.17 & 70.9 \\
mean (SD) & $(8.9)$ & $(8.8)$ & $(9.26)$ & $(8.9)$ & $(8.6)$ \\
Height, cm & 167.74 & 167.10 & 166.81 & 167.63 & 165.96 \\
mean (SD) & $(10.96)$ & $(11.31)$ & $(11)$ & $(11.25)$ & $(10.96)$ \\
Weight, kg & 93.86 & 92.97 & 91.81 & 93.35 & 93.14 \\
mean (SD) & $(25.24)$ & $(24)$ & $(24.51)$ & $(24.31)$ & $(25.41)$ \\
BMI, kg/m ${ }^{2}$ & 32.54 & 32.65 & 32.23 & 32.63 & 33.02 \\
mean (SD) & $(6.46)$ & $(6.55)$ & $(6.25)$ & $(6.46)$ & $(6.82)$ \\
Sex, $\mathrm{n}(\%)$ & & & & & \\
Male & $24(48)$ & $29(46)$ & $26(45)$ & $28(47)$ & $21(40)$ \\
Female & $26(52)$ & $34(54)$ & $32(55)$ & $32(53)$ & $31(60)$ \\
BMI, $\mathrm{n}(\%)$ & & & & & \\
$\quad$ Normal weight ${ }^{*}$ & $2(4)$ & $2(3.2)$ & $3(3.4)$ & $2(3.3)$ & $2(3.8)$ \\
Overweight ${ }^{\dagger}$ & $16(32)$ & $20(31.7)$ & $21(36.2)$ & $19(31.7)$ & $16(30.8)$ \\
Obese ${ }^{\ddagger}$ & $30(60)$ & $37(58.7)$ & $33(56.9)$ & $35(58.4)$ & $30(57.7)$ \\
Marital status, $\mathrm{n}(\%)$ & & & & & \\
$\quad$ Married & $37(74)$ & $49(79)$ & $43(75)$ & $47(78)$ & $40(77)$ \\
Divorced & $2(4)$ & $2(3)$ & $2(4)$ & $2(3)$ & $1(2)$ \\
Widowed & $10(20)$ & $10(16)$ & $11(19)$ & $10(17)$ & $10(19)$ \\
Single & $1(2)$ & $1(2)$ & $1(2)$ & $1(2)$ & $1(2)$ \\
\hline$N$
\end{tabular}

$N$ variability due to incomplete data. ${ }^{*}$ Body mass index (BMI) $18.5 \mathrm{~kg} / \mathrm{m}^{2}$ to $24.9 \mathrm{~kg} / \mathrm{m}^{2}$; ${ }^{\dagger} \mathrm{BMI} 25 \mathrm{~kg} / \mathrm{m}^{2}$ to $29.9 \mathrm{~kg} / \mathrm{m}^{2} ;{ }^{\sharp} B M I>30 \mathrm{~kg} / \mathrm{m}^{2}$ (62). LONG Longitudinal; PD1 Postoperative day 1; PD2 Postoperative day 2; PD3 Postoperative day 3; Preop Preoperative

0.80 to $0.90(41)$ and internal consistency in the present study was $\alpha=0.87$.

\section{Procedure}

The secretaries of participating surgeons from the Kingston General Hospital orthopedic service were contacted to gain the identity information of potential participants. Each identified patient was called, and study participation was detailed where patients provided initial verbal consent of participation. Consenting patients had a preoperative assessment arranged where they completed the SF-MPQ, PCS, SPOMS and MMSE. These patients were contacted via telephone on the evening before their surgery to confirm the time of surgery. Arrangements were made to meet $2 \mathrm{~h}$ before surgery at the Same Day Admission Centre, at which time the written consent was collected and a 10 min data collection interview was conducted. The postoperative assessments were conducted on each day that the patients were in the hospital following surgery. Postoperatively, patients were assessed between 12:00 and 14:00 on consecutive postoperative days because it coincided with hospital lunchtime, a time at which the assessment would be as unobtrusive to care as possible. Patients completed the questionnaire package at bedside, which included the SFMPQ, PCS, SPOMS and MMSE. The MMSE was only completed for the preoperative and postoperative day 1 , and all patients met the MMSE criteria of greater than 24. Although there was noted variance in patients' length of stay, only data collected on the first three postoperative days were examined because the mean length of stay for the current sample was four days. The sample sizes for postoperative days 4 and onwards were too restricted to be included in meaningful analyses. Following discharge, a review of each patient's medical chart was conducted. 
TABLE 2

Means and SDs for the nondemographic measures

\begin{tabular}{|c|c|c|c|c|}
\hline Measure & $\mathbf{n}$ & Range & Mean & SD \\
\hline \multicolumn{5}{|l|}{ Overall assessment } \\
\hline Pain & 50 & $0-19.67$ & 7.72 & 5.40 \\
\hline Catastrophizing & 50 & $0-18.00$ & 4.75 & 4.96 \\
\hline Negative mood & 50 & $0-42.67$ & 7.80 & 9.17 \\
\hline \multicolumn{5}{|c|}{ Preoperative assessment } \\
\hline Pain & 63 & $0-22.00$ & 5.57 & 6.47 \\
\hline Catastrophizing & 63 & $0-36.00$ & 7.13 & 7.32 \\
\hline Negative mood & 63 & $0-50.00$ & 14.44 & 13.00 \\
\hline \multicolumn{5}{|c|}{ Postoperative day 1 assessment } \\
\hline Pain & 58 & $0-34.00$ & 8.40 & 7.47 \\
\hline Catastrophizing & 57 & $0-28.00$ & 5.12 & 5.69 \\
\hline Negative mood & 57 & $0-52.00$ & 9.46 & 11.38 \\
\hline \multicolumn{5}{|c|}{ Postoperative day 2 assessment } \\
\hline Pain & 60 & $0-39.00$ & 7.88 & 8.02 \\
\hline Catastrophizing & 60 & $0-28.00$ & 5.26 & 6.55 \\
\hline Negative mood & 60 & $0-70.00$ & 9.98 & 14.90 \\
\hline \multicolumn{5}{|c|}{ Postoperative day 3 assessment } \\
\hline Pain & 52 & $0-30.00$ & 7.90 & 6.90 \\
\hline Catastrophizing & 52 & $0-52.00$ & 4.96 & 7.93 \\
\hline Negative mood & 52 & $0-26.00$ & 7.02 & 7.48 \\
\hline
\end{tabular}

$N$ variability due to incomplete data

\section{RESULTS}

Descriptive analyses

Means and SDs for all measures were calculated for longitudinal and intraday data (Table 2). The mean pain, catastrophizing and negative mood scores, which are examined below, were generated from the longitudinal data. The average score of the SF-MPQ for the present study was 7.72. This score is lower, but comparable with relevant normative scores, such as 10 for rheumatoid arthritis, 12 for OA and arthritis, and 14 for postoperative pain (39). The mean pain scores in the current study fall in the general range that is expected based on the above normative scores. The mean catastrophizing total score for the current study was 4.75. The rumination, helplessness and magnification subscale scores were $2.76,1.39$ and 0.60 , respectively. These scores are lower than would be expected given the PCS normative data that are available for catastrophizing, which suggest mean scores of 22, 9, 3.9 and 9.3 for the total scale, and rumination, magnification and helplessness subscales, respectively $(18,28)$. The average negative mood score in the current study was 7.8 for the total SPOMS and 2.25, $0.91,0.67,3.33$ and 0.84 for the tension-anxiety, depressiondejection, anger-hostility, fatigue-inertia and confusionbewilderment, respectively. The total mean negative mood score is higher than would be expected, given the normative mean score of 4.61 (41). In addition, the tension-anxiety and fatigue-inertia subscale mean scores are higher than the normative data of 1.44 and 1.73 , respectively (41). The depressiondejection, anger-hostility and confusion-bewilderment subscale mean scores are lower than would be expected given the normative data of $1.19,0.65$ and 0.99 , respectively (41). It is important to note that the normative mean scores reported for pain, catastrophizing and negative mood are based on younger adults, and norms based on younger adults may not be appropriate for comparison with older persons. Gagliese and
TABLE 3

Correlations among three study variables: Negative mood, catastrophizing (CAT) and pain

\begin{tabular}{|c|c|c|c|}
\hline & Negative mood & CAT & Pain \\
\hline \multicolumn{4}{|c|}{ Overall correlations } \\
\hline Negative mood & - & $0.63^{* *}$ & $0.43^{* \star}$ \\
\hline CAT & & - & $0.53^{* \star}$ \\
\hline Pain & & & - \\
\hline \multicolumn{4}{|c|}{ Preoperative correlations } \\
\hline Negative Mood & - & $0.53^{* *}$ & 0.21 \\
\hline CAT & & - & $0.35^{* \star}$ \\
\hline Pain & & & - \\
\hline \multicolumn{4}{|c|}{ Postoperative day 1 correlations } \\
\hline Negative Mood & - & $0.79^{* *}$ & $0.37^{\star \star}$ \\
\hline CAT & & - & $0.39^{\star \star}$ \\
\hline Pain & & & - \\
\hline \multicolumn{4}{|c|}{ Postoperative day 2 correlations } \\
\hline Negative Mood & - & $0.73^{\star *}$ & $0.43^{* \star}$ \\
\hline CAT & & - & $0.53^{\star \star}$ \\
\hline Pain & & & - \\
\hline \multicolumn{4}{|c|}{ Postoperative day 3 correlations } \\
\hline Negative Mood & - & $0.63^{* *}$ & $0.45^{\star \star}$ \\
\hline CAT & & - & $0.57^{\star \star}$ \\
\hline Pain & & & - \\
\hline
\end{tabular}

${ }^{* *} P<0.01$. Negative mood was assessed by the Shortened Version of Profile of Mood States without the vigor-activity subscale (41); CAT was assessed by the Pain Catastrophizing Scale (18) and pain was assessed by the Short Form - McGill Pain Questionnaire (39)

Melzack (42) found that the SF-MPQ had high reliability and that the subscales offered comparable approximations of pain levels with older adults. No older adult normative data were identified for catastrophizing and negative mood, as measured by the PCS and SPOMS, respectively. As a result, the differences between the normative mean scores for these variables and the mean scores found in the current study may be attributable to differences between normative mean scores for younger and older adults.

\section{Relationships among variables}

Correlations examined the associations between the demographic variables and pain, catastrophizing and negative mood. These analyses were completed for the longitudinal and intraday subgroups (Table 3).

Longitudinal data: Women reported higher negative mood $(r[50]=0.34 ; \mathrm{P}<0.05)$, catastrophizing $(r[50]=0.39 ; \mathrm{P}<0.01)$ and pain $(r[50]=0.41 ; \mathrm{P}<0.01)$ than men. Negative mood was strongly associated with catastrophizing $(r[50]=0.63 ; \mathrm{P}<0.01)$, as was pain $(r[50]=0.43 ; \mathrm{P}<0.01)$. Catastrophizing was also associated with higher pain $(r[50]=0.53 ; \mathrm{P}<0.01)$.

Preoperative intraday data: Women reported higher negative mood $(r[63]=0.30 ; \mathrm{P}<0.05)$, catastrophizing $(r[63]=0.26$; $\mathrm{P}<0.05)$ and pain $(r[63]=0.29 ; \mathrm{P}<0.05)$ than men. Younger patients reported greater pain $(r[63]=-0.25 ; \mathrm{P}<0.05)$. Patients with greater negative mood reported more catastrophizing $(r[63]=0.53 ; \mathrm{P}<0.01)$. Catastrophizing was associated with pain $(r[63]=0.35 ; \mathrm{P}<0.01)$.

Postoperative day 1 intraday data: Once again, women reported greater negative $\operatorname{mood}(r[57]=0.41 ; \mathrm{P}<0.01)$, catastrophizing $(r[57]=0.40 ; \mathrm{P}<0.01)$ and pain $(r[57]=0.33 ; \mathrm{P}<0.05)$ 
than did men. Greater negative mood was robustly associated with catastrophizing $(r[57]=0.79 ; \mathrm{P}<0.01)$ but moderately with pain $(r[57]=0.37 ; \mathrm{P}<0.01)$. Catastrophizing was again associated with greater pain $(r[57]=0.39 ; \mathrm{P}<0.01)$.

Postoperative day 2 intraday data: Negative mood experienced was associated with catastrophizing $(r[60]=0.73 ; \mathrm{P}<0.01)$ and pain $(r[60]=0.43 ; \mathrm{P}<0.01)$. Patients with greater catastrophizing also experienced more pain $(r[60]=0.53 ; \mathrm{P}<0.01)$.

Postoperative day 3 intraday data: Patients with greater negative mood experienced more catastrophizing $(r[52]=0.63$; $\mathrm{P}<0.05)$ and pain $(r[52]=0.46 ; \mathrm{P}<0.01)$.

\section{Regression models}

Standard multiple regression analyses examined the association of preoperative and postoperative psychosocial variables on preoperative and postoperative pain. As shown in Table 4, catastrophizing and negative mood for the preoperative and postoperative intraday data were used to predict pain for each day. In all regression models, demographic information was entered only if significantly associated with the modeled dependent variable.

Preoperative pain: Preoperative pain was regressed onto preoperative catastrophizing and negative mood. Age and sex were entered as predictors because they were significantly related to preoperative pain. This regression model was significant, $\mathrm{R}^{2}=0.23, \mathrm{~F}(4,58)=4.28, \mathrm{P}<0.01$. Age and catastrophizing emerged as significant predictors of preoperative pain, $\beta=-0.26, t=-2.25, P<0.05$ and $\beta=0.32, t=2.28, P<0.05$, respec tively. Younger age and higher preoperative catastrophizing are associated with higher pain preoperatively. Follow-up regression analysis of preoperative pain examined the unique contributions of the catastrophizing subscales. While the regression model was significant, $\mathrm{R}^{2}=0.12, \mathrm{~F}(3,59)=2.78, \mathrm{P}<0.05$, no significant predictors of preoperative pain emerged, $\mathrm{P}>0.13$. This finding is due to inter-relationship among the three catastrophizing subscales (rumination was associated with helplessness $(r[63]=0.76 ; \mathrm{P}<0.01)$ and magnification $(r[63]=0.28 ; \mathrm{P}<0.05)$, and helplessness was associated with magnification $(r[63]=0.31 ; \mathrm{P}<0.05)$, indicating that for this analysis the subscales cannot be differentiated.

Postoperative day 1 pain: Catastrophizing and negative mood were highly correlated on postoperative day $1(r[57]=0.79$, $\mathrm{P}=0.01)$. Therefore, a composite distress score was calculated by averaging the mean scores on the PCS and SPOMS and centering that value. Higher scores on this composite measure reflected greater distress. Postoperative day 1 pain was regressed on postoperative day 1 distress. Sex was added as a predictor because it was significantly correlated with postoperative day 1 pain. This model was significant, $R^{2}=0.20$, $F(4,44)=2.75, \mathrm{P}<0.05$. No significant predictors emerged, $P>0.06$. Distress, however, was marginally significant $(\beta=0.26$, $t=1.96, \mathrm{P}=0.06$ ), indicating that higher distress on postoperative day 1 was associated with higher pain on postoperative day 1 .

Postoperative day 2 pain: Catastrophizing and negative mood were highly correlated on postoperative day $2(r[60]=0.73$, $\mathrm{P}=0.01)$. As previously completed, a composite distress score was calculated and centred for the PCS and SPOMS. Higher scores on this composite measure reflected greater distress. Postoperative day 2 pain was regressed on postoperative day 2 distress. No demographic variables were entered into the regression model. This model was significant, $R^{2}=0.32, F(3,45)=7.04$, $\mathrm{P}<0.01$. Postoperative day 2 distress emerged as a significant
TABLE 4

Regression analyses predicting pain

\begin{tabular}{|c|c|c|}
\hline Variable & Total $\mathbf{R}^{2}$ & Beta \\
\hline Preoperative pain $(n=62)$ & 0.23 & \\
\hline Catastrophizing & & $0.32^{*}$ \\
\hline Negative mood & & -0.05 \\
\hline Age & & $-0.26^{*}$ \\
\hline Sex & & 0.22 \\
\hline Preoperative pain $(n=62)$ & 0.12 & \\
\hline Rumination & & 0.06 \\
\hline Helplessness & & 0.29 \\
\hline Magnification & & 0.05 \\
\hline Postoperative day 1 pain $(n=48)$ & 0.20 & \\
\hline Distress composite score & & 0.26 \\
\hline Sex & & 0.17 \\
\hline Postoperative day 2 pain $(n=48)$ & 0.32 & \\
\hline Distress composite score & & $0.54^{\star \star}$ \\
\hline Postoperative day 3 pain $(n=34)$ & 0.32 & \\
\hline Catastrophizing & & -0.06 \\
\hline Negative mood & & $0.53^{\star *}$ \\
\hline Postoperative day 3 pain $(n=34)$ & 0.36 & \\
\hline Tension-anxiety & & $0.37^{* *}$ \\
\hline Depression-dejection & & -0.012 \\
\hline Anger-hostility & & -0.04 \\
\hline Fatigue-inertia & & $0.49^{* \star}$ \\
\hline Confusion-bewilderment & & -0.16 \\
\hline
\end{tabular}

${ }^{*} P<0.05 ;{ }^{* *} P<0.01$. Demographic information was entered only if significantly associated with the modeled dependent variable

predictor of postoperative day 2 pain, $\beta=0.54, t=4.18$ and $\mathrm{P}<0.01$. As a result, higher distress on postoperative day 2 was associated with higher pain on postoperative day 2 .

Postoperative day 3 pain: Postoperative day 3 pain was regressed on postoperative day 3 catastrophizing and negative mood. No demographic variables were included in the regression equation. This model was significant, $\mathrm{R}^{2}=0.32, F(4,30)=3.46, \mathrm{P}<0.05$. Postoperative day 3 negative mood emerged as a significant predictor of postoperative day 3 pain, $\beta=0.53, t=3.31, \mathrm{P}<0.01$, indicating that negative mood is related to higher pain on postoperative day 3. Follow-up analyses regressed postoperative day 3 pain on the negative mood subscales. Tensionanxiety and fatigue-inertia emerged as predictors of postoperative day 3 pain, $\beta=0.37, t=2.64, P<0.05$ and $\beta=0.49$, $t=3.80, \mathrm{P}<0.01$, respectively.

Predicting postoperative pain from preoperative variables Standard multiple regression was used to examine preoperative prediction of postoperative outcome. Postoperative days 1, 2 and 3 pain were regressed on preoperative pain, catastrophizing and negative mood, with results summarized in Table 5 . The models that regressed postoperative days 1, 2 and 3 pain on preoperative pain, catastrophizing and negative mood were not significant.

Time effects on pain, pain catastrophizing and negative $\operatorname{mood}$

Repeated measures ANOVA examined time effects. Two sets of repeated measures ANOVA were computed. Significant differences on pain, catastrophizing and negative mood across the preoperative and three postoperative days were examined. The time effect was significant, $F(13,21)=4.24, \mathrm{P}<0.01$, and follow-up univariate analyses indicated that pain and negative 


\section{TABLE 5}

Multiple regression analyses predicting pain

\begin{tabular}{lcc}
\hline Variable & Total $\mathbf{R}^{2}$ & Beta \\
\hline Postoperative day 1 pain $(\mathrm{n}=49)$ & 0.06 & \\
Preoperative pain & & 0.13 \\
Preoperative catastrophizing & & 0.19 \\
Preoperative negative mood & & 0.00 \\
Postoperative day 2 pain ( $\mathrm{n}=49)$ & 0.07 & \\
$\quad$ Preoperative pain & & 0.13 \\
Preoperative catastrophizing & & 0.15 \\
Preoperative negative mood & & 0.10 \\
Postoperative day 3 pain ( $\mathrm{n}=42)$ & 0.12 & \\
Preoperative pain & & 0.30 \\
Preoperative catastrophizing & & -0.12 \\
Preoperative negative mood & & 0.14 \\
\hline
\end{tabular}

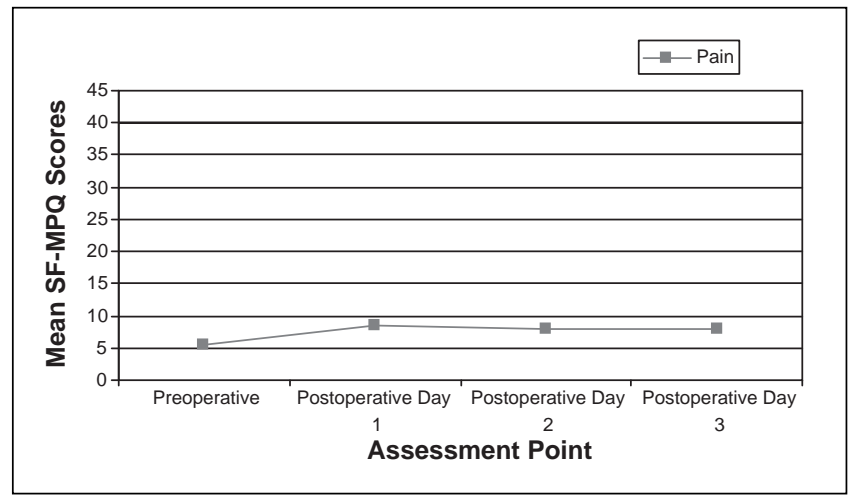

Figure 1) Time effects on the Short Form - McGill Pain Questionnaire (SF-MPQ), showing the range of possible mean scores (0 to 45)

mood differed significantly as a function of time, $F>3.42$, $\mathrm{P}<0.05$.

Time effects on pain: Pairwise comparisons based on estimated marginal means showed that pain on postoperative days 1 through 3 was higher than preoperative pain, $\mathrm{P}<0.05, \mathrm{P}<0.01$ and $\mathrm{P}<0.05$, respectively (Figure 1 ).

Time effects on negative mood: Pairwise comparisons based on estimated marginal means showed that negative mood was higher preoperatively than on postoperative days 2 and 3 , and is higher on postoperative day 1 than on postoperative day 3 $(\mathrm{P}<0.05, \mathrm{P}<0.01$ and $\mathrm{P}<0.05$, respectively) (Figure 2$)$.

\section{DISCUSSION}

The primary goal of the present study was to determine if postoperative catastrophizing and negative mood predicted postoperative pain, whether there were changes in these variables over time in a TKA sample, and if preoperative variables would predict postoperative pain. The findings support a number of the hypotheses that are discussed in turn.

\section{Catastrophizing and TKA pain}

Catastrophizing was associated with greater pain pre- and postTKA. This finding supports previous pain and surgical literature $(25,27,36)$ and is a novel contribution to the TKA literature. In addition, catastrophizing was a lone predictor of

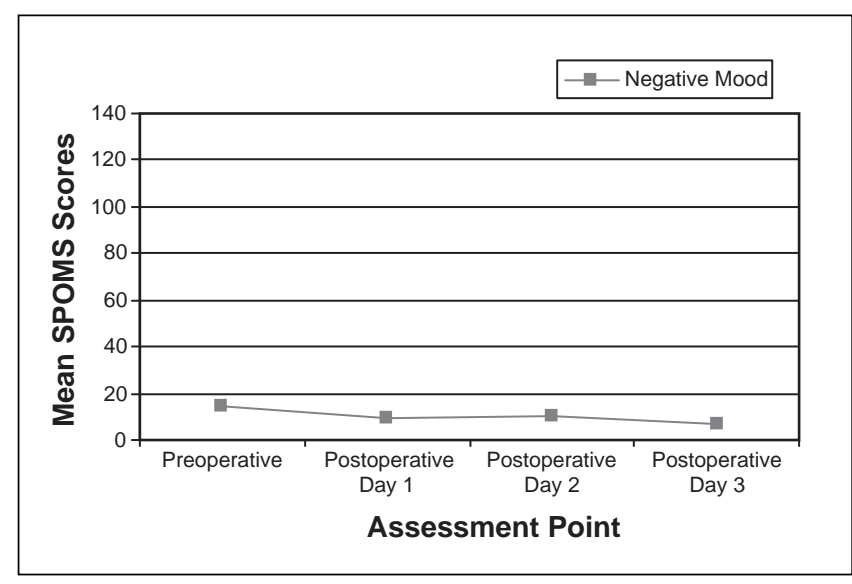

Figure 2) Time effects on the Shortened Version of Profile of Mood States (SPOMS), showing the range of possible mean scores (0 to 140)

greater pain preoperatively and was also uniquely associated with postoperative day 2 pain. It was also noted that catastrophizing was positively associated with pain during all assessment periods for the present study.

It is not possible to comment on the causality of the paincatastrophizing relationship from correlational analyses. However, previous research has posed the question of whether pain increases the risk for catastrophizing (43). Sullivan et al (18) have suggested that catastrophizing is a temporally stable variable primarily based on earlier research with undergraduate samples. Others have indicated that individuals may develop enduring schemas regarding the threat of pain and their ability to effectively cope with the pain $(44,45)$. Catastrophizing postTKA may be better understood as a negative cognitive appraisal process that fluctuates with the amount of pain that is experienced because preoperative catastrophizing does not predict future pain occurrence in this sample (44).

Catastrophizing did not uniquely predict pain on postoperative days 1 and 3 . This finding may be due to decreasing sample sizes and reduced threat value of TKA. Previous research demonstrating a more consistent prediction of pain from catastrophizing has been based on a younger cohort of patients (mean age $31 \pm 1.2$ years) undergoing ACL repair (32). Recent findings indicate that there are age-related differences in pain severity and perceived control of pain (23), such that older patients report lower pain ratings and the development of various positive pain coping strategies. Moreover, there may be qualitative differences in the recovery expectations and trajectories following ACL repair and TKA that the current data cannot examine. In particular, patients undergoing TKA are generally informed and expect decreased pain and increased QoL, and these expectations may act to moderate the pain/catastrophizing relationship (1). The current study did not examine patient expectations and thus cannot directly examine such a hypothesis.

A recent study examining the relationship between catastrophizing and chronic pain associated with sickle cell disease concluded that high and low catastrophizing was unrelated to sickle cell disease-related pain (46). The authors suggested that the pain-catastrophizing relationship may not be as robust in chronic pain samples. They base this suggestion on findings that chronic pain may be less threatening as one habituates to it or develops useful coping strategies $(44,46)$. Similarly, 
Boersma and Linton (47), in their examination of chronic musculoskeletal pain, established that the pain-catastrophizing relationship was statistically significant when assessed in patients who had experienced pain for less than three years when compared with patients who had experienced pain for more than three years. These findings suggest that catastrophizing may be more relevant to the acute pain experience and may explain why catastrophizing did not uniquely predict pain toward the end of patients' recovery in this sample. The current study did not examine possible pain habituation and coping stategies and cannot directly examine this hypothesis.

\section{Negative mood and pain}

Negative mood was positively and consistently related to pain, and emerged as a unique and strong predictor of pain on postoperative day 3 . These results support the negative mood-pain literature $(27,30)$, and adds to the surgical and pain literature as the initial study to identify this relationship among TKA patients $(27,30,48)$. Of the tension-anxiety and fatigue-inertia subscales, fatigue-inertia was the strongest predictor of pain on postoperative day 3. This association between anxiety and pain is well established $(20,49)$, and fatigue is a common postoperative issue $(50,51)$. Although not directly examined in the present study, anecdotal study reports have suggested that patients often complain of sleep difficulties, which may be attributed to some combination of patient pain, hospital milieu or feelings of distress (52).

\section{Age and pain}

Age was inversely associated with pain, where younger patients reported higher pain. Age differences in pain scores have previously been reported $(53,54)$ but studies examining the underlying causes of age differences in pain are equivocal and sporadic. Gibson and Helme (53) suggest that cultural factors, such as stoicism, lack of familiarity with verbal pain descriptors and the practice of pain reporting, may result in under-reporting of pain among older adults. In addition, older patients may falsely believe that pain is part of the natural trajectory and under report (53). Recently, LaChapelle and Hadjistavropoulos (23) found that increasing age is related to decreased pain severity and the perception of greater control over pain. The literature suggests that under-reporting of pain by the older adult cohort may be commonplace and that older patients may perceive greater pain control and thus lower pain severity $(23,53)$.

\section{Catastrophizing and negative mood}

Catastrophizing was positively and strongly related to negative mood in this sample in several assessment periods. The strength of the interrelationship between these variables on postoperative days 1 and 2 required that the regression models compute a composite measure for analyses. This finding adds to the clinical and experimental pain literature, which to date illustrates an association between catastrophizing and heightened emotional distress in response to pain $(25,27,44)$, and is the first empirical examination of the inter-relationship between catastrophizing and negative mood in a TKA population.

The high association between catastrophizing and negative mood supports Sullivan et al's (55) early suggestion that catastrophizing may be better classified among the category of mood and anxiety disorders in older samples, specifically indicating that it may be a subcomponent of such larger order factors as trait anxiety and negative affectivity (55). Trait anxiety has been identified as a possible precursor to catastrophic thoughts (55). In contrast, Crombez et al (56) suggested that catastrophizing contributes independently to pain, although this suggestion pertains specifically to the depression-catastrophizing relationship. The high catastrophizing-negative mood association in the current study is largely manifested by the catastrophizing and fatigue-inertia subscale of the SPOMS. There has been little research to date on such an association in the literature except for mentions in the oncology research examining catastrophizing and fatigue (57). In the current study, the catastrophizing-fatigue relationship informs new avenues for future research and may indicate that for an older adult sample, the two constructs are conceptually similar.

\section{Preoperative catastrophizing}

Preoperative catastrophizing did not predict postoperative pain. A recent study (32) has shown that preoperative pain catastrophizing was a significant predictor of pain immediately following the surgery and one week after surgery. To test the concept that catastrophizing can act like a trait-like construct (27), preoperative catastrophizing was examined for prospective effects on postoperative pain in this older sample of surgical patients. The null finding of this hypothesis brings into question the reliability of such effects. The preoperative catastrophizing scores are considered low when contrasted against other reported scores. It is likely that such a range restriction reduces the variance accounted for in the prospective analyses. As an alternative line of evidence suggests, catastrophizing may be more appropriately considered as a readily modifiable, situation-specific cognitive style $(27,45)$. This suggestion, that catastrophizing is acquiescent to modification, is interesting. In the current sample, preoperative catastrophizing had little predictive value on future reports of pain. Perhaps catastrophizing in this OA TKA sample may be acting as a situationspecific reactive appraisal process activated to more extreme levels when pain is elevated, as is the case of the postoperative assessments.

The current study shows that across the perioperative assessment of TKA, age, preoperative catastrophizing, and postoperative negative mood and catastrophizing were associated with poorer preoperative and postoperative pain. These results have clinical implications for the care of these surgical patients. Awareness of the impact of negative mood and especially fatigue is suggested for medical staff. It is suggested that preoperative education regarding potential postoperative fatigue is offered to patients undergoing TKA, and that the psychological versus physiological antecedents of postoperative fatigue is acknowledged (58).

Sullivan et al (26) indicated that interventions targeting catastrophizing could facilitate positive gains in pain reduction and negative mood. Recent research suggests that modification to the catastrophic thinking about pain may be a mechanism underlying positive changes in pain report (59). From these suggestions, it is recommended that brief cognitive behavioural therapy techniques may facilitate reduction in catastrophic thinking with the goal of reducing postoperative pain. However, it is difficult to imagine what extent of meaningful consolidation and benefit such training may be able to achieve with patients in a heightened state of physiological and psychological distress. These suggestions await future empirical examination. 


\section{Limitations}

The present data are limited by the fluctuating size of the sample, which places restrictions on the number of covariates in the regression models. Although our present analyses were sufficiently powered, a larger sample would allow examination of other variables of potential importance in surgical settings. Variables such as social support, ethnicity or physician/nurse engagement are notably excluded from the present study. It is likely that such variables would provide a stronger index of explained variance in the current regression models. Second, correlational designs prohibit any causal conclusions. The present data can provide no information on whether catastrophizing or negative mood states cause greater pain or if pain is the initiator of postoperative psychosocial distress. The study relied exclusively on patient self-report, which is obviously reliant on retrospective reports of feelings and experiences (39). In spite of such criticisms, self-reported pain remains the gold standard in both clinical and experimental pain research. To help control for variation in self-report, all assessments were standardized to time periods to stabilize situational factors such as the assessment environment (ie, the same time every day, in the same patient room).

\section{Future research}

Future research could utilise measures that do not rely on selfreport, such as physician assessments, observations and reports of pain behaviours from a significant other or nurse. Furthermore, coding of facial expressions of pain or other pain behaviour (38) during active physiotherapy and at rest would provide another form of assessment of TKA postoperative pain. The impact and interrelationship of fatigue, catastrophizing and pain can be more fully understood using an objective measurement of fatigue, such as the number of hours of sleep and consumption of sleeping pills.

Future TKA research could examine the associations of the psychosocial and pain variables in a larger prospective design. It is suggested that patients be assessed on more than one occasion during the pre- and postoperative surgery/recovery period. Indeed, the present study is limited to data encompassing acute postoperative TKA pain and cannot inform readers on how patients manage other TKA indices of positive acute postoperative outcomes. As an example, it would be of interest to examine the associations between completion and/or adherence to the TKA physiotherapy protocol (ie, early ambulation, stair climbing, etc), pain, catastrophizing and negative mood states. Indeed, catastrophizing, assessed before general exercise sessions, has been significantly correlated with negative mood, pain and with reduction in the amount of weight lifted (43). Furthermore, regression analyses showed that catastrophizing predicted reductions in weight lifted even after controlling for pain and negative mood, suggesting that catastrophizing is associated with objective indices of activity intolerance associated with pain.

Pain-related response expectancies could be examined in a postoperative TKA sample. Previous surgical research has established that preoperative expectancies of pain are significantly related to the experience of postoperative pain (60). It is possible that preoperative expectancies may be a predictive variable in regard to prospective pain report or that it may act as a mediator between pain and other postoperative psychosocial variables. Finally, collection of pain medication type and consumption levels, as well as the type of analgesia protocol during surgery may also be important variables to explore in the examination of postoperative pain and physical recovery.

\section{CONCLUSION}

TKA procedures are increasing, with approximately 15,000 carried out annually in Canada $(1,13)$, making it the third most common procedure performed among older adults in Canada (61). Estimates of poor TKA outcome are in the range of $10 \%$ to $15 \%$ (12). The current research examining psychosocial predictors of acute postoperative pain is the first to assess the associations and prediction of acute TKA pain reporting based on catastrophizing and negative mood states. The results replicate and extend the pain and surgical literature by demonstrating that catastrophizing and negative mood, specifically the tension-anxiety and fatigue-inertia components, are robustly related to and predictive of postoperative pain. Younger age within this older adult cohort is related to and predictive of greater pain. Catastrophizing and negative mood are strongly associated in a postoperative context. Surprisingly, preoperative catastrophizing was not associated with postoperative pain. Among these novel findings, the relationship between fatigue and postoperative pain is novel in a TKA postoperative sample. When these results are combined, psychosocial variables are shown to be consistently associated with patient experience for acute postoperative TKA outcomes like pain. The current study design limits the possibility of drawing conclusions about the causal statements on such effects. Consequently, future research should explore these relationships using a longitudinal design that emphasizes later follow-up in a larger sample because sample size attrition over the course of the various assessment periods is likely.

ACKNOWLEDGEMENTS: The authors gratefully acknowledge the contribution of the study participants, the student volunteers who assisted with data collection and the research team for their clinical expertise.

FUNDING: Funds to conduct this research were provided by a Queen's University Advisory Research Committee grant awarded to Dean Tripp. Maya Roth was supported, in part, by an Ontario Graduate Scholarship.

\section{REFERENCES}

1. Brander VA, Stulberg AD, Adams AD, et al. Predicting total knee replacement pain: A prospective, observational study. Clin Orthop Relat Res 2003;416:27-36.

2. Health Canada. Canada's Aging population: A health report prepared by Health Canada and the Interdepartmental Committee of Aging and Seniors Issues. <www.hcsc.gc.ca/seniors-aines/pubs/fed_paper/pdfs/fedpager_e.pdf> (Version current at June 8, 2007).

3. About Canada. Aging and the population. <www.mta.ca/faculty/arts/canadian_studies/english/about/aging/> (Version current at June 8, 2007).

4. Blixen CE, Kippes C. Depression, social support, and quality of life in older adults with osteoarthritis. Image J Nurs Sch 1999;31:221-6.

5. Creamer P. Osteoarthritis pain and its treatment. Curr Opin Rheumatol 2000;12:450-5.

6. Creamer P, Flores R, Hochberg MC. Management of osteoarthritis in older adults. Clin Geriatr Med 1998; 14:435-54.

7. Powell M. Orthopaedic Nursing. New York: Longman Group Limited, 1976. 
8. The Arthritis Society. Types of arthritis.

<www.arthritis.ca/types\%20 of\%20arthritis/default.asp?s=1> (Version current at June 8, 2007).

9. Dunbar MJ. Subjective outcomes after knee arthroplasty. Acta Orthop Scand 2001;72:1-63.

10. Heck DA, Robinson RL, Partridge CM, Lubitz RM, Freund DA. Patient outcomes after knee replacement. Clin Orthop Relat Res 1998;356:93-110.

11. Kreder HJ, Grasso P, Williams JI, et al. Provider volume and other predictors of outcome after total knee arthroplasty: A population study in Ontario. Can J Surg 2003;46:15-22.

12. Ashworth MA, Brule C, Day A, et al. The Development of an Orthopedic Waiting List Algorithm for Elective Total Hip and Total Knee Replacement Surgery. Technical report prepared for the Canadian Health Services Research Foundation, 2002.

13. Joshi AG, Gill G. Total knee arthroplasty in nonagenarians. J Arthroplasty 2002;17:681-4.

14. Creamer P, Lethbridge-Cejku M, Hochberg, MC. Factors associated with functional impairment in symptomatic knee osteoarthritis. Rheumatology 2000;39:490-6.

15. Ginsberg B. Pain management in knee surgery. Orthop Nurs 2001;20:37-41.

16. Morrison RS, Magaziner J, McLaughlin MA, et al. The impact of post-operative pain on outcomes following hip fracture. Pain 2003;103:303-11.

17. Classification of chronic pain. Descriptions of chronic pain syndromes and definitions of pain terms. Prepared by the International Association for the Study of Pain, Subcommittee on Taxonomy. Pain Suppl 1986;3:S1-226.

18. Sullivan MJL, Bishop S, Pivik J. The pain catastrophizing scale: Development and validation. Psychol Assess 1995;7:524-34.

19. Sullivan MJ, Neish NR. Catastrophic thinking and the experience of pain during dental procedures. J Indiana Dent Assoc 2000;79:16-9.

20. Gilles ML, Smith LN, Parry-Jones WL. Postoperative pain assessment and management in adolescents. Pain 1999;79:207-15.

21. Romano JM, Turner JA. Chronic pain and depression: Does the evidence support a relationship? Psychol Bull 1985;97:18-34.

22. Paradowski PT, Bergman S, Sundén-Lundius A, Lohmander LS, Roos EM. Knee complaints vary with age and gender in the adult population. Population-based reference data for the Knee injury and Osteoarthritis Outcome Score (KOOS). BMC Musculoskelet Disord 2006;7:38.

23. LaChapelle DL, Hadjistavropoulos T. Age-related differences among adults coping with pain: Evaluation of a developmental life-context model. Can J Behav Sci 2005;37:123-37.

24. Rustoen T, Wahl AK, Hanestad BR, Lerdal A, Paul S, Miaskowski C. Age and experience of chronic pain: Differences in health and quality of life among younger, middle-aged, and older adults. Clin J Pain 2005;21:513-23.

25. Keefe FJ, Lefebvre JC, Egert JR, et al. The relationship of gender to pain, pain behavior, and disability in osteoarthritis patients: The role of catastrophizing. Pain 2000;87:325-34

26. Keefe FJ, Lefebvre JC, Egert JR, Affleck G, Sullivan MJ, Caldwell DS. Theoretical perspectives on the relations between catastrophizing and pain. Clin J Pain 2001;17:52-64.

27. Sullivan MJL, Rodgers WM, Kirsch I. Catastrophizing, depression and expectancies for pain and emotional distress. Pain 2001;91:147-54.

28. Sullivan MJL, Tripp DA, Santor D. Gender differences in pain and pain behavior: The role of catastrophizing. Cognit Ther Res 2000;24:121-34.

29. Jacobsen PB, Butler RW. Relation of cognitive coping and catastrophizing to acute pain and analgesic use following breast cancer surgery. J Behav Med 1996;19:17-29.

30. Feldman SI, Downey G, Schaffer-Neitz R. Pain, negative mood, and perceived support in chronic pain patients: A daily diary study of people with reflex sympathetic dystrophy syndrome. J Consult Clin Psychol 1999;67:776-85.
31. Banks SR, Kerns, RD. Explaining high rates of depression in chronic pain: A diathesis-stress hypothesis. Psychol Bull 1996;119:95-110.

32. Pavlin DJ, Sullivan MJL, Freund PR, Roesen K. Catastrophizing: A risk factor for postsurgical pain. Clin J Pain 2005;21:83-90.

33. Granot M, Goldstein Ferber, S. The roles of pain catastrophizing and anxiety in the prediction of postoperative pain intensity: A prospective study. Clin J Pain 2005;21:439-45.

34. Geisser ME, Robinson ME, Richardson C. A time series analysis of the relationship between ambulatory EMG, pain, and stress in chronic low back pain. Biofeedback Self Regul 1995;20:339-55.

35. Martin MY, Bradley LA, Alexander RW, et al. Coping strategies predict disability in patients with primary fibromyalgia. Pain 1996;68:45-53.

36. Keefe FJ, Smith SJ, Buffington AL, et al. Recent advances and future direction in the biopsychosocial assessment and treatment of arthritis. J Consult Clin Psychol 2002;70:640-55

37. Folstein MF, Folstein SE, McHugh PR. Mini-mental state: A practical method for grading the cognitive state of patients for the clinician. J Psychiatr Res 1975;12:189-98.

38. Feldt KS, Oh, HL. Pain and hip fracture outcomes for older adults. Orthop Nurs 2000;19:35-44.

39. Melzack R. The short-form McGill Pain Questionnaire. Pain 1987;30:191-7.

40. Turk DC, Melzack R, eds. Handbook of Pain Assessment. New York: Guilford Press, 1992.

41. Shacham S. A shortened version of the profile of mood states. J Pers Assess 1983;47:305-6.

42. Gagliese L, Melzack R. Age differences in the quality of chronic pain: A preliminary study. Pain Res Manag 1997;2:157-62.

43. Sullivan MJ, Rodgers WM, Wilson PM, Bell GJ, Murray TC, Fraser SN. An experimental investigation of the relation between catastrophizing and activity intolerance. Pain 2002;100:47-53.

44. Jensen MP, Turner JA, Romano JM, et al. Coping with chronic pain: A critical review of the literature. Pain 1991;47:249-83.

45. Spanos NP, Brown JM, Jones B. et al. Cognitive activity and suggestions for analgesia in the reduction of reported pain. J Abnorm Psychol 1981;90:554-61.

46. Citero VD, Levenson JL, McClish DK, et al. The role of catastrophizing in sickle cell disease - The PiSCES project. Pain 2007; (e-pub ahead of print).

47. Boersma K, Linton SJ. How does persistent pain develop? An analysis of the relationship between psychological variables, pain, and function across stages of chronicity. Behav Res Ther 2005;43:1495-507.

48. Tripp DA, Stanish WD, Reardon G, Coady C, Sullivan MJ. Comparing postoperative pain experiences of the adolescent and adult athlete after anterior cruciate ligament surgery. J Athl Train 2003;38:154-7.

49. Bélanger E, Melzack R, Lauzon P. Pain of first-trimester abortion: A study of psychosocial and medical predictors. Pain 1989;36:339-50.

50. Kehlet H, Dahl JB. Anesthesia, surgery, and challenges in postoperative recovery. Lancet 2003;362:1921-8.

51. Zalon ML. Correlates of recovery among older adults after major abdominal surgery. Nurs Res 2004;53:99-106.

52. Stoudemire A. Psychological and emotional reactions to illness and surgery. In: Lubin MF, Walker HK, Smith RB, eds. General Management of the Surgical Patient. Philadelphia: Lippincott, 1995:165-80.

53. Gibson SJ, Helme RD. Age-related differences in pain perception and report. Clin Geriatr Med 2001;17:433-56

54. Herr KA, Mobily PR. Complexities of pain assessment in the elderly: Clinical considerations. J Gerontol Nurs 1991;17:12-9. 


\section{Roth et al}

55. Sullivan MJ, Thorn B, Rodgers W, Ward LC. Path model of psychological antecedents to pain experience. Clin J Pain 2004;20:164-73.

56. Crombez G, Eccleston C, Vlaeyen JW, Vansteenwegen D, Lysens R, Eelen P. Exposure to physical movements in low back pain patients: Restricted effects of generalize. Health Psychol 2002;21:573-8.

57. Jacobsen PB, Anddryowski MA, Thors CL. Relationship of catastrophizing to fatigue among women receiving treatment for breast cancer. J Consult Clin Psychol 2004;72:355-61.

58. Salmon P, Hall GM. Postoperative fatigue is a component of the emotional response to surgery: Results of multivariate analysis. J Psychosom Res 2001;50:325-35.
59. Burns JW, Kubilus A, Bruehl S, Harden RN, Lofland K. Do changes in cognitive factors influence outcome following multidisciplinary treatment for chronic pain? A cross-lagged panel analysis. J Consult Clin Psychol 2003;71:81-91.

60. Montgomery GK, Bovbjerg DH. Presurgery distress and specific expectancies predict postsurgery outcomes in surgery patients confronting breast cancer. Health Psychol 2004;23:381-7.

61. Millar WJ. Hip and knee replacement. Health reports/Statistics Canada, Canadian Centre for Health Information, 2002;14:37-50

62. Gilmore J. Body mass index and health. Health reports/Statistics Canada, Canadian Centre for Health Information, 1999, 11:31043. 


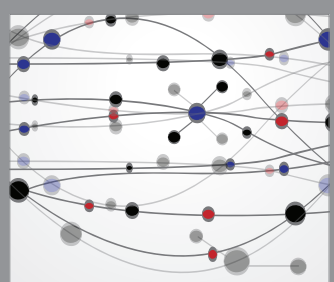

The Scientific World Journal
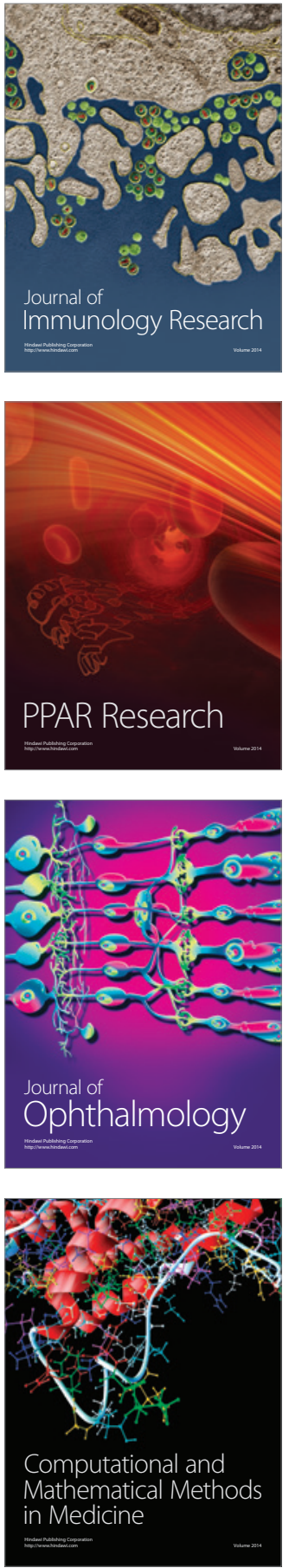

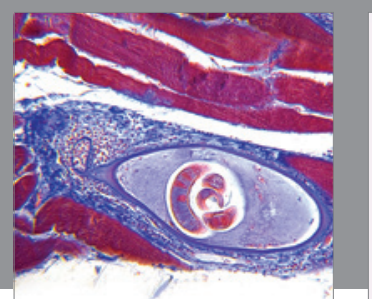

Gastroenterology Research and Practice

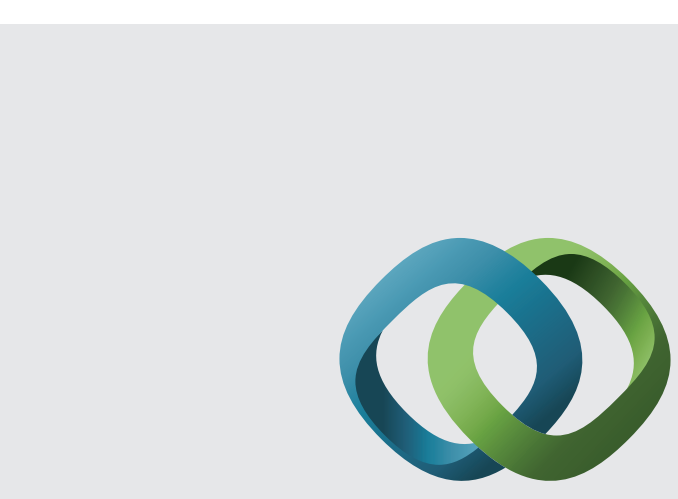

\section{Hindawi}

Submit your manuscripts at

http://www.hindawi.com
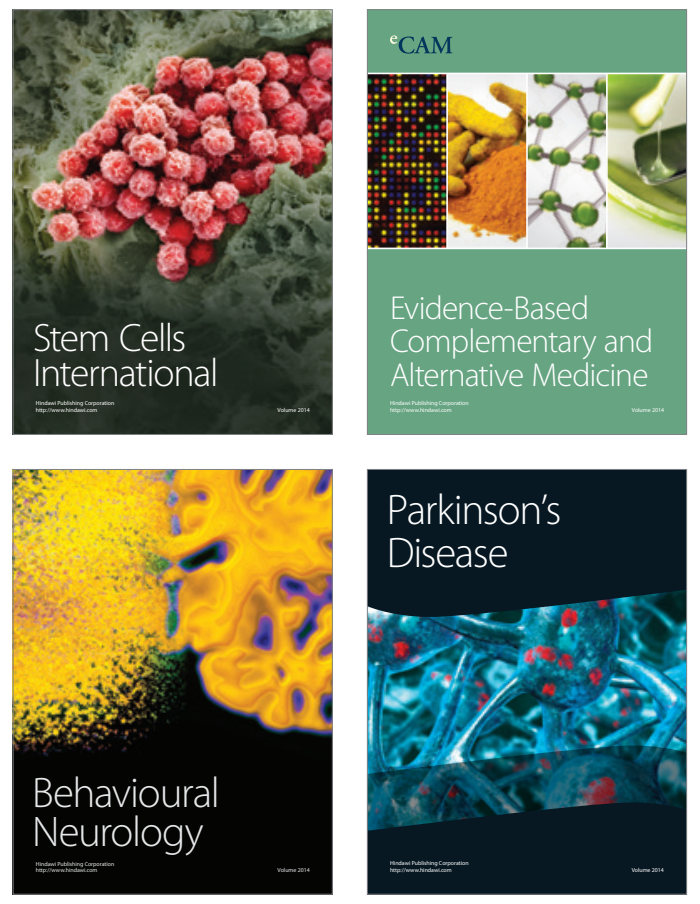
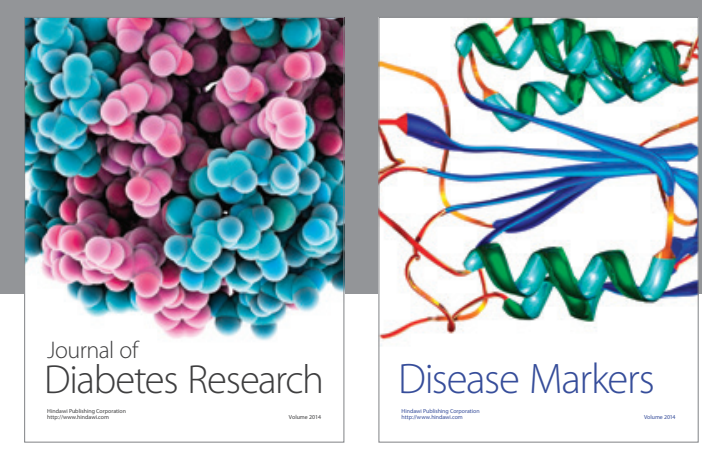

Disease Markers
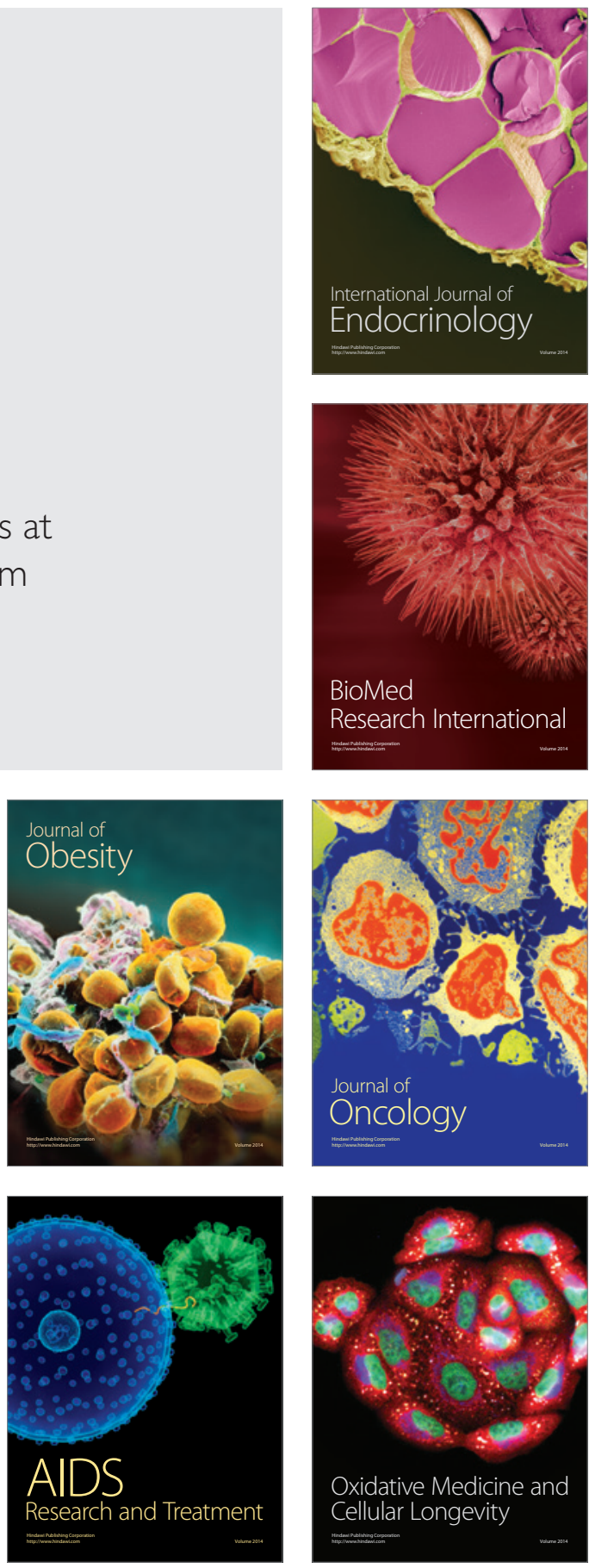